\title{
Sibilant harmony in Santiago Tz'utujil (Mayan)
}

\author{
Paulina Lyskawa \& Rodrigo Ranero*
}

\begin{abstract}
We analyze sibilant harmony in the Santiago Atitlán dialect of Tz'utujil (Mayan), a phenomenon that was briefly described by Dayley (1985). Novel data show that the obligatory harmony process (i) is asymmetrical (triggered only by [+ant] sibilants), (ii) progressive, and (iii) applies long-distance. Furthermore, we argue that the process is not stem-controlled. In contextualizing the phenomenon within the typology of sibilant harmony (Hansson 2010), we conclude that it is unique. Finally, we suggest that Santiago Tz'utujil sibilant harmony has been stable diachronically because the target segment $/ \mathrm{J} /$ is always in the stressed syllable, thus being salient in the input during acquisition.
\end{abstract}

Keywords. sibilant harmony; consonantal harmony; progressive harmony; phonology; typology; Mayan; Tz'utujil; K'ichean

1. Introduction. Tz'utujil (ISO 639-3) is a K'ichean Mayan language spoken in Guatemala, primarily in several towns on the southern side of Lake Atitlán. The San Juan la Laguna and San Pedro la Laguna dialects share many properties and are the best described of all Tz'utujil dialects (Dayley 1985; Pérez Mendoza \& Hernández Mendoza 2001 for San Juan Tz’utujil; García Ixmatá 1997; 1998 for San Pedro Tz'utujil; among others). The variety spoken in Santiago Atitlán (henceforth $S T z$ ') has only received attention recently in the literature (Levin, Lyskawa \& Ranero 2020; Baron, Lyskawa \& Ranero 2020; Lyskawa \& Ranero 2021a; 2021b) and is the most phonologically innovative of all Tz'utujil dialects (Dayley 1985). Dayley (1985) provides a sketch of STz' phonology and posits a rule of optional sibilant harmony (1). All of Dayley's examples are shown in (2): ${ }^{1}$

(1) Sibilant harmony in STz' (adapted from Dayley 1985: 36)

$\int \rightarrow \mathrm{s} / \ldots \mathrm{s} \ldots{ }_{-}$Optional

(2) Examples of sibilant harmony in STz' (adapted from Dayley 1985: 36)
a. / /
$\rightarrow$ [Jkmsasa]
COM-B3S- $\sqrt{\text { die-CAUS-PASS-INTR }}$

\footnotetext{
* Authors share first-authorship and are listed alphabetically. We thank our consultants Rosario, Andrea, Rosalía, and Andreína Ramírez for their generosity in sharing their language with us. Thank you to Masha Polinsky, Omer Preminger, Bill Idsardi, Marisa Fried, and Pedro Mateo Pedro for their help, and Avery Ozburn, John DuBois, Romelia Mó Isém, Andrew Lamont, Danny Law, Carlos Humberto Cú Cab, Arthur Thompson, Peter Jurgec, and the audience at the 2021 LSA Annual Meeting for comments. We acknowledge financial support from a Jacobs Research Funds group grant to Lyskawa, Ranero \& Fried, a Cosmos Club Foundation scholarship to Ranero, SSHRC support \# 752-2016-0180 to Lyskawa, and NSF Grant \# BCS 1563129 to Maria Polinsky. All errors are our own. Authors: Paulina Lyskawa, University of Maryland, College Park (lyskawa@umd.edu) and Rodrigo Ranero, University of Maryland, College Park (rranero@umd.edu).

${ }^{1} \mathrm{We}$ follow the Mayanist convention of labelling ergative/genitive agreement as Set A and absolutive agreement as Set $\mathrm{B}$. Abbreviations are as follows: $\mathrm{A}=$ Set $\mathrm{A}$ agreement; $\mathrm{ADJ}=$ adjective; $\mathrm{AP}=$ antipassive; $\mathrm{B}=$ Set $\mathrm{B}$ agreement; CAUS $=$ causative; $\mathrm{CLF}=$ classifier; $\mathrm{COM}=$ completive aspect; $\mathrm{I}=$ intransitive; $\mathrm{INC}=$ incompletive aspect; $\mathrm{INCH}=$ inchoative; INTR = intransitive status suffix; ITV $=$ intransitivizer; NMLZ = nominalizer; $\mathrm{P}=$ plural; PASS $=$ passive; POS $=$ positional $; \mathrm{POT}=$ potential aspect; $\mathrm{PROG}=$ progressive auxiliary; $\mathrm{RN}=$ relational noun; $\mathrm{S}=$ singular; $\mathrm{TR}=$ transitive. Note that the B3S agreement morpheme is null. We use $<>$ when transcribing orthographically.
} 

b. / / $-\varnothing-\chi 0 s q '-V f-a /$
$\rightarrow\left[\int \chi \mathbf{s}\right.$ Gisa $]$
'It was cleaned.' COM-B3S- $\sqrt{ }$ clean-PASS-INTR

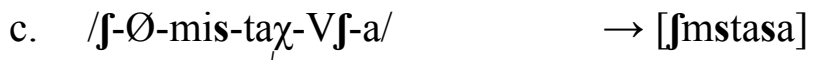
COM-B3S- $\sqrt{\text { sweep-PASS-PASS-INTR }}$
'It was swept.'

Sibilant harmony appears to be unique to STz' among Tz'utujil dialects. There is no such process in San Juan or San Pedro Tz'utujil: ${ }^{3}$
No sibilant harmony in San Juan Tz'utujil (Pérez Mendoza \& Hernández Mendoza 2001)
a. / $/ \mathcal{-} \varnothing$-so $\chi$ we- $\int /$ COM-B3s- $\sqrt{\text { float}-P A S S}$
b. /ruu-kam-sa-f-ik/ A3S- $\sqrt{\text { die-CAUS-PASS-NMLZ }}$
$\rightarrow\left[\right.$ so $\left.\chi w e \int\right]$
'It was floated'
$\rightarrow$ [rkamsaafiik]
(p. 396; entry for < sojwexik $>$ 'to float') 'its killing'
(p. 166; entry for <kamsaxik> 'to kill')

No sibilant harmony in San Pedro Tz'utujil (García Ixmatá 1998)
a. $\quad / \int$ - $\varnothing$-war-isaa- $\int-\mathrm{i} /$ $\rightarrow$ [jwarisafi]
'It was made to sleep.' COM-B3S- $\sqrt{\text { sleep-CAUS-PASS-INTR }}$
(p. 105)
b. / $\int$-sir-V6a?- $-\mathrm{i}$ - $/ \quad \rightarrow[$ siri6afi] 'A spherical thing was put somewhere. COM- $\sqrt{ }$ spherical.POS-CAUS.POS-PASS-INTR

Novel STz' data in section 3 lead us to modify the rule description in (1) to the following:

$$
\begin{aligned}
& \text { Sibilant harmony in STz' } \\
& \int \rightarrow[+ \text { ant }] /[+ \text { ant, }+ \text { strid }] \ldots-
\end{aligned}
$$

In section 4, we show that STz' sibilant harmony is typologically unique. Our STz' data come from in-person elicitations from 2017-2019 with four consultants in Guatemala, as well as online video elicitations from 2020-2021. Whenever the syntactic environment is helpful for understanding the data, we provide the target word in its sentential context.

2. Consonantal inventory. In Table 1, we provide the consonantal inventory in Tz'utujil:

\begin{tabular}{|c|c|c|c|c|c|c|c|}
\hline & bilabial & alveolar & $\begin{array}{c}\text { alveo- } \\
\text { affricate }\end{array}$ & $\begin{array}{c}\text { palato- } \\
\text { alveolar }\end{array}$ & velar & postvelar & glottal \\
\hline simple stop & $\mathrm{p}$ & $\mathrm{t}$ & $\mathbf{t s}$ & $\mathbf{t} \boldsymbol{j}$ & $\mathrm{k}$ & $\mathrm{q}$ & \\
\hline glottalized stop & $\mathrm{b}$ & $\mathrm{d}$ & $\mathbf{t s}^{\prime}$ & $\mathbf{t j}^{\prime}$ & $\mathrm{k}^{\prime}$ & $\mathrm{q}^{\prime}$ & ? \\
\hline fricative & & $\mathbf{s}$ & & $\boldsymbol{J}$ & & $\chi$ & \\
\hline nasal & $\mathrm{m}$ & $\mathrm{n}$ & & & & & \\
\hline lateral & & $\mathrm{l}$ & & & & & \\
\hline trill & & $\mathrm{r}$ & & & & & \\
\hline semivowel & $\mathrm{w}$ & & & $\mathrm{j}$ & & & \\
\hline
\end{tabular}

Table 1. Consonantal inventory in San Juan Tz'utujil (Dayley 1985); applicable to STz'

\footnotetext{
2 There appear to be two passive suffixes here, the completive passive /-ta $\chi$ / (Lyskawa \& Ranero 2021a; Dayley 1985: 122; García Ixmatá 1998: 106) and the regular passive /-VJ/. Our STz' consultants rejected this example. It is possible that this example involves the verbal root 'to forget' /mest/ and the translation provided is incorrect.

${ }^{3}$ In (3), we provide the underlying forms and gloss of the affixes as given in Dayley (1985) for San Juan Tz'utujil; /-S/ for the passive, /-sa/ for the causative, and /-ik/ for the nominalizer (Dayley uses the term "infinitive"; see p. 105). In (4) we provide the underlying forms and gloss of the affixes as given in García Ixmatá 1998 for San Pedro Tz'utujil: /- $\mathrm{S} /$ for the passive, /-isaa/ for the causative, and /-V6a?/ for the causative that attaches to positional roots (where the $\mathrm{V}$ is a copy of the root vowel).
} 
Sibilants in STz' occur in many roots (mostly of the form $\mathrm{CVC}$ ) and in the following affixes:

List of affixes containing sibilants in STz
POT: / $\mathrm{ft}-/$
COM: $/ \int-/$

The vowel that surfaces in the passive morpheme is not predictable and appears to be lexically idiosyncratic. With this background in mind, we now turn to the description of sibilant harmony in STz'.

3. Empirical description. In this section, we expand on Dayley's (1985) description of sibilant harmony in STz' and arrive at the process described by the SPE-style rule in (7).

$$
\begin{aligned}
& \text { Sibilant harmony in STz' } \\
& \int \rightarrow[+ \text { ant }] /[+ \text { ant, }+ \text { strid }] \ldots
\end{aligned}
$$

We use a descriptive rule format for ease of exposition, making no specific commitment as to the representation of harmony processes in the grammar in general (e.g., via agreement-bycorrespondence in OT - Rose \& Walker 2004; see Rose 2011 for discussion). The sibilant harmony process in (7) has several properties that we will illustrate and discuss in turn in sections 3.1-3.4 and 4.1:

(8) Properties of sibilant harmony in STz'

a. The only trigger is [+ant, + strid]; [-ant, + strid] is not a trigger.

b. It is progressive (the trigger precedes the target), not regressive or bi-directional.

c. It is long-distance; trigger and target need not be in adjacent morphemes.

d. The target is not morpheme-specific.

e. It is not stem-controlled.

Sibilant harmony in STz' appears to be obligatory today, in contrast to Dayley 1985's description of data collected almost 50 years ago. The obligatory nature of the process today is shown throughout via examples that were deemed unacceptable by our consultants.

3.1. THE ONLY TRIGGER IS [+ANT, +STRID]. Dayley (1985) shows that $/ \mathrm{s} /$ is a trigger for harmony in STz' (2). Novel data in (10) show that all [+ant] sibilants /s, $\widehat{\text { ts}}, \widehat{t s} / /$ are triggers. First consider the baseline data below:

$$
\begin{aligned}
& \text { /nk-at-kon-Vf-a/ } \rightarrow \text { [nkatkonofa] } \\
& \text { INC-B2S-Vlook.for-PASS-INTR }
\end{aligned}
$$

Now observe the behavior of the [-ant] sibilant /J/ in the passive morpheme /-VJ/ when there is a [+ant] sibilant in the root:

(10) General [+ant, +strid] trigger in the root
a. $/ \int-\varnothing$-qas-Vf-a/ $\rightarrow\left[\int\right.$ qasasa $] / *\left[\int q a s a \int a\right]$ COM-B3S- $\sqrt{\text { cut-PASS-INTR }}$

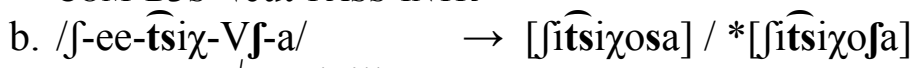 COM-B3P- $\sqrt{\text { speak.ill-PASS-INTR }}$

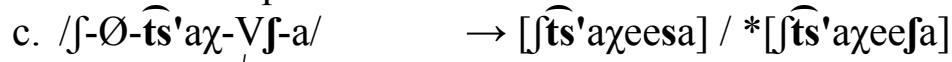 COM-B3S- $\sqrt{\text { smash-PASS-INTR }}$
'It was cut.'
'They were spoken ill of.'
'It was smashed.' 
In (10a-c) above, harmony is triggered by a segment in the root. However, the trigger need not be a root segment - the /s/ in the causative suffix /-saa/ is also a trigger, as shown in (12):

(11) Causativization with /-saa/
a. / $/$ - $\varnothing$-ten-a/
$\rightarrow[$ tena $]$
'She bathed.'
COM-B3S- $\sqrt{\text { bathe-INTR }}$

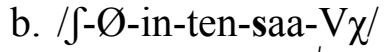
COM-B3S-A1S- $\sqrt{\text { bathe-CAUS-TR }}$
$\rightarrow[$ Jintensaa $]$
'I bathed her.'

(12) $[+$ ant, + strid $]$ trigger in causative suffix
a. / $/$ - $\varnothing$-ten-saa-V $\int-\mathrm{a} /$ COM-B3S- $\sqrt{ }$ bathe-CAUS-PASS-INTR
b. / -at-moj-saa-V $\int-\mathrm{a} /$
$\rightarrow\left[\int\right.$ tensaasa $] / *\left[\int\right.$ tensaa $\left.] a\right]$
'She was bathed.' COM-B2S- $\sqrt{\text { blind-CAUS-PASS-INTR }}$
c. $/ \int-\varnothing$-no $\chi-\mathbf{s a a}-\mathrm{V} \int-\mathrm{a} / \mathrm{C} \quad \rightarrow\left[\int\right.$ no $\left.\chi \mathbf{s a a s a}\right] / *\left[\int\right.$ no $\left.\chi \mathbf{s a a} \int \mathrm{a} a\right]$
COM-B3s- $\sqrt{\text { fill-CAUS-PASS-INTR }}$
$\rightarrow[$ Jatmojsaasa $] / *[$ Jatmojsaa $a]$
'You were hypnotized.'
'It was filled.'

The examples below show that [-ant] sibilants are not triggers: the [-ant] sibilant in the completive / $\int-/$ and B2P morpheme /if-/ does not trigger assimilation on [+ant] sibilants in the root:

(13) $[$-ant, +strid] is not a trigger

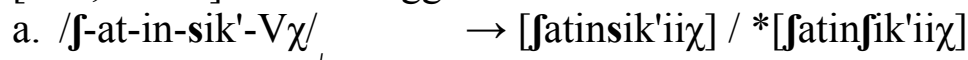 COM-B2S-A1S- $\sqrt{\text { call-TR }}$
b. $/ \mathrm{k}$-if-in-sik'-V $\chi / \quad \rightarrow[$ kifinsik'ii $\chi / *[$ kifinfik'ii $\chi]$ INC-B2P-A1S- $\sqrt{\text { call-TR }}$
'I called you.'
'I am calling you all.'

The examples below show further that [-ant] sibilants are not triggers. Here, $/ \int, \widehat{t} \int, \widetilde{t}^{1} /$ segments in a root do not trigger assimilation on the /s/ segment of the causative suffix /-saa $/:^{4}$

(14) $[$-ant, +strid] is not a trigger
a. $/ \int$-in-a- $\chi \chi$ ow-saa-V $\chi / \rightarrow\left[\int\right.$ na $\left.\int \chi o w s a a \chi\right] / *\left[\int \mathrm{na} \chi \chi \mathrm{ow} \int \mathrm{aa} \chi\right]$ COM-B1S-A2s- $\sqrt{\text { dance-CAUS-TR }}$

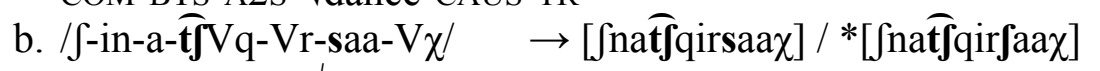 COM-B1S-A2s- $\sqrt{\text { dry-INCH-CAUS-TR }}$

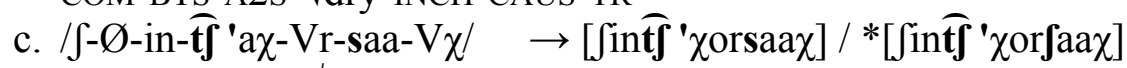 COM-B3S-A1S- $\sqrt{ }$ clean-INCH-CAUS-TR
'You got me dry.'
'I cleaned it.'

We conclude that the harmony process in STz' is asymmetric: only [+ant] sibilants are triggers.

3.2. THE HARMONY IS PROGRESSIVE. If the harmony process were bi-directional, we would expect that [-ant] sibilants in the prefixal field would assimilate to a [+ant] sibilant to their right. There are three candidate targets in the prefixal field for the assimilation process: (i) the completive aspect morpheme $/ \int-/$, (ii) the $/ \mathrm{J} /$ segment in the potential aspect morpheme $/ \int \mathrm{t}-/$, and (iii) the $/ \mathrm{J} /$ segment in the B2P agreement morpheme /if-/. As shown below (and throughout the paper), the $/ \mathrm{J} /$ in these prefixes never surfaces as [+ant]. We cannot assess the behavior of the other [-ant] sibilants $/ \mathrm{t}_{\mathrm{f}} /$ and $/ \mathrm{t}^{\prime} /$ within the prefixal field, since no STz' prefix contains these segments:

\footnotetext{
${ }^{4}$ Assuming that all STz' roots have an underlying vowel, the vowel in $/ \mathrm{t} \mathrm{Vq} /$ 'dry' cannot be determined, since it is always deleted; see Dayley (1985: 45) for STz' vowel syncope and England \& O. Baird 2017 for Mayan phonotactics.
} 
(15) STz' sibilant harmony is not regressive; $/ \delta /$ in the prefixal field
a. /k-if-in-sik'-V $\chi /$ INC-B2P-A1S- $\sqrt{\text { call-TR }}$
$\rightarrow[$ kifinsik'ii $] / *[$ kisinsik'ii $]$

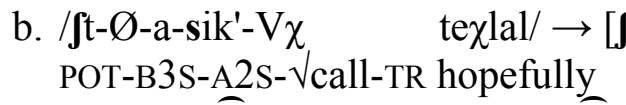
c. $/ \int$-ee-ruu-tsi $\chi-V \chi / \quad \rightarrow[$ firtsi $\chi$ uo $\chi] / *[$ sirtsi $\chi$ uo $\chi]$ COM-B3P-A3S- $\sqrt{\text { speak.ill-TR }}$
d. $/ \int-i \int-$ nuu-ts'et/
COM-B2P-A1s- $\sqrt{\text { see }}$
'I am calling you all.'
$\rightarrow[$ [ifnuts'et $]$ / *[fisnuts' et $]$ / *[sisnuts'et $]$ / *[sifnuts'et $]$ 'I saw you all.'

The data below show that [-ant] sibilants in the root also fail to undergo assimilation with a [+ant] sibilant on their right:

(16) STz' sibilant harmony is not regressive; $/ \int, \widehat{\mathrm{t} f}, \widehat{\mathrm{t}}^{1} /$ in the root

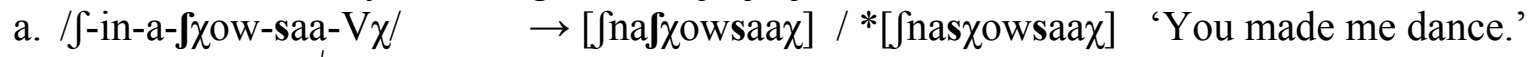 COM-B1S-A2S- $\sqrt{\text { dance-CAUS-TR }}$
b. $/ \int-\varnothing$-in-re $\int-V r-s a a-V \chi / \rightarrow\left[\right.$ finre $\left.\int e r s a a \chi\right] / *\left[\int i n r e s e r s a a \chi\right]$ COM-B3S-A1s- Vgreen-INCH-CAUS-TR

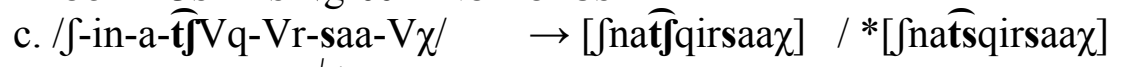 COM-B1S-A2s- $\sqrt{\text { dry-INCH-CAUS-TR }}$

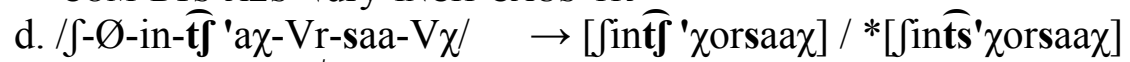 COM-B3S-A1s- $\sqrt{\text { clean-INCH-CAUS-TR }}$
'I made it green.'
'You got me dry.'
'I cleaned it.'

The following examples illustrate most clearly the progressive nature of the harmony process: only [-ant] sibilants following a [+ant] sibilant trigger undergo assimilation, whereas root-internal [-ant] sibilants preceding it do not:

(17) Sibilant harmony is progressive, not regressive

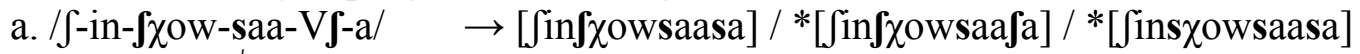 COM-B1s- $\sqrt{\text { dance-CAUS-PASS-INTR }}$

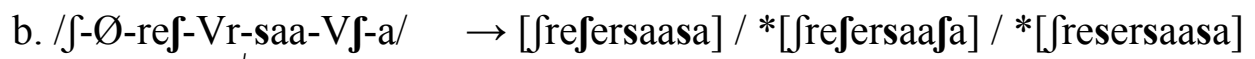 COM-B3S- $\sqrt{\text { green-INCH-CAUS-PASS-INTR }}$

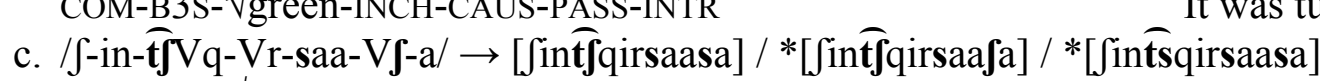 COM-B1s- $\sqrt{\text { dry-INCH-CAUS-PASS-INTR }}$

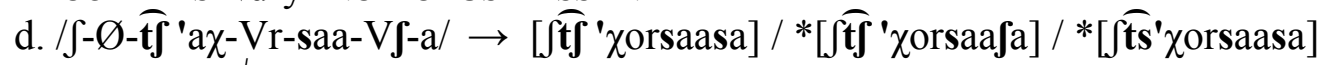 COM-B3S- $\sqrt{\text { clean-INCH-CAUS-PASS-INTR }}$
'It was cleaned.'

We conclude that sibilant harmony in STz' is exclusively progressive. ${ }^{5}$

\footnotetext{
${ }^{5}$ No prefixes in STz' contain a [ +ant] sibilant. It is therefore impossible to assess whether sibilant harmony is triggered from the prefixal field. It was suggested to us that compounds may serve as an empirical testing ground to assess the directionality of STz' sibilant harmony. While an in-depth exploration of STz' compounds and their prosodic properties is pending (see Dayley 1985: 55 for San Juan Tz'utujil compounds) harmony does not seem to apply here:

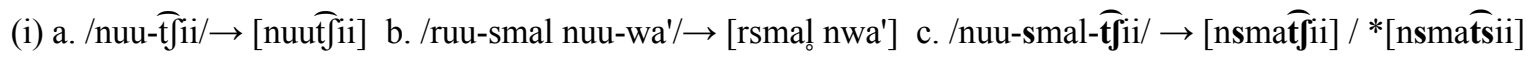 A1s-mouth A3s-hair A1s-head 'my mouth' 'my hair'
d. $/ \mathrm{at} \int \mathrm{a} / \rightarrow[\mathrm{at} \mathrm{a}]$
man
e. $/$ suots' $/ \rightarrow[$ suots' $]$
'man'
bat
'bat'
A1s-hair-mouth
'my beard'

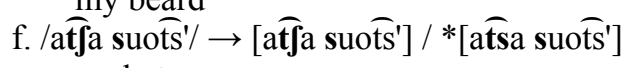
man bat
'Batman'


3.3. THE HARMONY IS LONG-DISTANCE. All examples assessed so far have shown that [-ant] sibilants assimilate to a [+ant] sibilant that is part of an immediately preceding morpheme. In this section, we show that the process is long-distance: the trigger and the target need not be in adjacent morphemes. This fact, and our discussion in 3.4 below, argue against an analysis that would take the STz' phenomenon to involve a phonologically-conditioned morphological alternation. ${ }^{6}$ The crucial examples involve positional roots that are derived into transitive verbal stems. These stems can be passivized with /-VJ/, whose / $/$ / segment is a target. Positional roots are a distinct category of roots in Mayan languages that are distinguished morphosyntactically and semantically from other root classes, like nominal and verbal roots (Henderson 2019; Polian 2017). Take for example the positional root/ $/ \mathrm{er} /$, which surfaces in stems that are derived via suffixes that combine exclusively with positional roots:

(18) Positional roots and derivations
a. / zer-Cik/ $\rightarrow$ [zerzik]
lay.down.POS-ADJ.POS

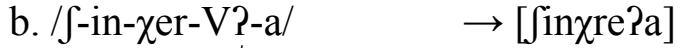 COM-B1S- $\sqrt{\text { lay.down.POS-ITV.POS-INTR }}$

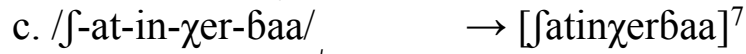 COM-B2S-A1s- $\sqrt{\text { lay.down.POS-CAUS.POS }}$

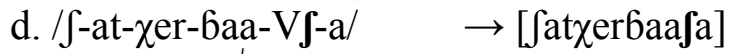 COM-B2s- $\sqrt{\text { lay.down.POS-CAUS.POS-PASS-INTR }}$
'laid down (on the ground)'
'I laid down (on the ground).'
'I laid you down (on the ground).'
'You were laid down (on the ground).'

Below, we use positional roots that include a [+ant] sibilant to show the long-distance nature of the harmony process. Observe that assimilation occurs, even though the causative morpheme /-baa/ separates the trigger and target:

(19) STz' sibilant harmony is long distance
a. / J-at-in-sin-baa/ $\rightarrow$ [ atinsinbaa] COM-B2S-A1S- Vundressed.POS-CAUS.POS
b. / -in-sin-6aa-V $\int-\mathrm{a} /$ COM-B1S- Vundressed.POS-CAUS.POS-PASS-INTR
c. / $\int$-at-in-tsel-6aa/ COM-B2S-A1s- $V_{\text {twisted.POS-CAUS.POS }}$
d. / $\int$-in-tsel-6aa-VJ-a/ COM-B1s- $\sqrt{ }$ twisted.POS-CAUS.POS-PASS-INTR
e. / -at-in-ts'u?-6aa/ COM-B2S-A1s- $\sqrt{\text { seated.POS-CAUS.POS }}$ $\rightarrow$ [ ${ }^{2}$ atints'u?baa $]$
'I undressed you.'
f. / $\int$-in-ts'u?-baa-VJ-a/ COM-B1s- $\sqrt{\text { seated.POS-CAUS.POS-PASS-INTR }}$
'I was undressed.'
'I twisted you.'
'I was twisted.'
'I sat you down.'

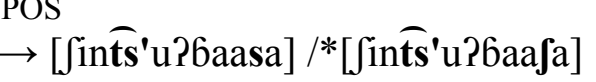
'I was sat down.'

We conclude that sibilant harmony in STz' applies long-distance.

\footnotetext{
This is consistent with the observation that sibilant harmony rarely applies across a compound boundary (see Hansson 2020).

${ }^{6}$ See Paster (2014) for the criteria that distinguish whether an alternation arises due to phonological processes or from morphological subcategorization.

${ }^{7}$ Two of our four consultants use an additional transitive suffix in this example type:
(i) $/ \int$-at-in- $\chi$ er-6aa- $V \chi /$
(two consultants)

COM-B2S-A1s- $\sqrt{ }$ lay.down.POS-CAUS.POS-TR
} 
3.4. THE TARGET IS NOT MORPHEME SPECIFIC. In all examples shown so far, the target has been the $/ \mathrm{J} /$ segment in the passive morpheme /-VS/. However, this is not the only morpheme in which the harmony process materializes. The $/ \mathrm{J} /$ segment in the nominalizer /-fik/ is also a target for the harmony process. This suffix attaches to a transitive stem and the resulting nominalization can be the complement of an auxiliary verb that is used in the progressive construction (Levin, Lyskawa \& Ranero 2020), as illustrated below:
a. / COM-B3S-A1S- $\checkmark$ buy one chicken
b. /ruu-m $\chi$ uon ki-loq'-fik i-k'ij A3S-PROG A3P-Vbuy-NMLZ P-many chicken
$\rightarrow$ [Jinloq' $\chi$ un ak'] 'I bought a chicken.'
'He is buying many chickens.'

A $/ \mathrm{J} /$ segment in the nominalizer assimilates to a [ + ant $]$ sibilant in the root:

(21) Target in nominalizer suffix
a. /ruu-sik'-fik/
$\rightarrow[$ rsik'sik $] / *[$ rsik'fik $]$
'his calling' A3S- $\sqrt{\text { call-PASS-NMLZ }}$
b. /ruu-tsaj-fik/
$\rightarrow[$ rtsajsik $] / *[$ rtsajjik $]$
'its seasoning'
A3s- $\sqrt{\text { season-NMLZ }}$

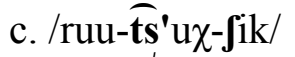
$\rightarrow\left[\widehat{r t s}^{\prime} \mathrm{u} \chi \mathbf{s i k}\right] / *\left[\widehat{r s s}^{\prime} \mathrm{u} \chi \int \mathrm{jik}\right]$
'his mocking'
A3s- $\sqrt{\text { mock-NMLZ }}$

An alternative interpretation of the data just described would posit that /- $\mathrm{fik} /$ is decomposable into two affixes - the passive /-VJ/ and a nominalizer /-ik/. ${ }^{8}$ In other words, this approach would require that nominalizations be derived from passivized stems. For example, Imanishi (2014) proposes this analysis for nominalizations in closely-related Kaqchikel (cf. Can Pixabaj 2015: 114-120 for K'iche'). If this analysis were correct for STz' as well, then the result of the harmony process would only materialize on the / $/$ / segment of the passive /-V $/$ /

However, this morphological decomposition is not justified for STz'. First, the STz' nominalizations never surface with the vowel that is part of the passive morpheme. Second, some Kaqchikel nominalizations come in two versions, with a different voice morpheme in each (passive versus antipassive). Observe that the nominalization in (22a) contains a passive morpheme, whereas the nominalization in (22b) has an antipassive:

\footnotetext{
8 The data in García Ixmatá (1998: 120-121) imply that CVC transitive roots in San Pedro Tz'utujil are nominalized directly via the nominalizer /-ik/, while derived transitives must be passivized first via the suffix /- $\int /$. This cannot be the correct generalization for STz', since some CVC transitives are nominalized via /-fik/ and others via /-ik/; see discussion below (compare (20) and (23)). Dayley (1985: 179) reports that in San Juan Tz'utujil, CVC roots are passivized via the infix / $-\chi-/$ and then undergo nominalization. We observe no such requirement in STz', given that in examples like (23b), the nominalizer attaches to an underived CVC root.
} 
Voice exponents are thus in complementary distribution in Kaqchikel nominalizations. In contrast, we have been unable to replicate similar data in STz' and examples like (22a-b) are not discussed by Dayley (1985) or García Ixmatá (1997; 1998). Thus, there is no evidence from voice alternations in Tz'utujil that the sibilant segment in the nominalizer is an exponent of voice. Finally, the nominalizer suffix surfaces without a sibilant segment altogether in some nominalizations: ${ }^{9}$

(23) Nominalization without sibilant
a. $/ \int-\varnothing$-in-tsaq
k'ij wej/ $\rightarrow$ [Sintsaq k'ij ßej]
'I made many tortillas.' COM-B3S-A1S- $\sqrt{\text { make many tortilla }}$

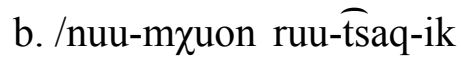
A1S-PROG A3S- $\sqrt{\text { make-NMLZ tortillas }}$
wej/ $\rightarrow$ [num $\chi$ uon rtsaqik $\beta$ ej] $] *[$ rtsaqfik] $*[$ rtsaqsik]
'I am making tortillas.'

The same can be observed with transitive roots that are passivized via the /-V $\mathrm{f} /$ suffix in general (see example (10c)):

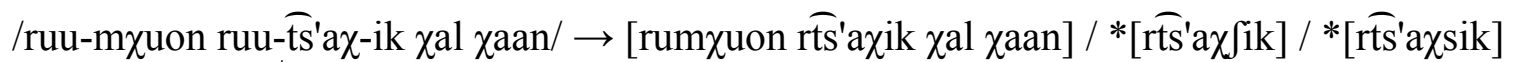

$$
\begin{aligned}
& \text { A3S-PROG A3s- } \sqrt{\text { smash-NMLZ that fly }} \\
& \text { 'She is smashing that fly.' }
\end{aligned}
$$

There is no morphophonological generalization regarding which roots combine with the form of the nominalizer that surfaces as [-ik] versus [- $\left.\int \mathrm{ik}\right] /[-\mathrm{sik}]$. We thus could not posit that the sibilant is present underlyingly and undergoes deletion in a specific environment. As a result, we propose that the nominalizer has two lexically conditioned allomorphs: the allomorph /-ik/ com-

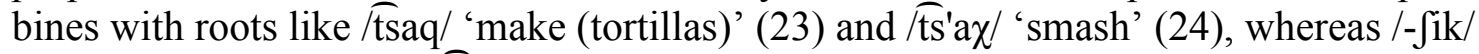
combines with roots like /ts'ux/ 'mock' (20b) and /loq'/ 'buy' (21c) (pace Levin, Lyskawa \& Ranero 2020: 341).

To summarize, sibilant harmony in STz' is not morpheme specific, since it targets (i) the $/ \mathrm{g} /$ segment in the passive /-V $/$ / and (ii) the $/ \mathrm{J} /$ segment in one of the allomorphs of the nominalizer, namely $/-\int \mathrm{ik} /$.

4. Typological contextualization. In this section, we lay out (and modify slightly) Hansson (2010)'s typologies of sibilant harmony systems and observe that the STz' pattern is an outlier. In section 4.1, we argue that the STz' phenomenon is an instance of progressive sibilant harmony that cannot be reduced to stem control, which is otherwise unattested. In section 4.2, we show that only one other language (Tlachichilco Tepehua) has been described as exhibiting harmony where only [ + ant] sibilants are triggers. The combination of having sibilant harmony that is (i) progressive and (ii) triggered only by [+ant] sibilants makes the STz' phenomenon unique. We end by suggesting that sibilant harmony in STz' has been diachronically stable because the target is always in the stressed syllable.

4.1. SibILANT HARMONY IN SANTIAGO TZ'UTUJIL IS NOT STEM-CONTROLLED. We established that STz' has the following sibilant harmony process:

$$
\begin{aligned}
& \text { Sibilant harmony in STz' } \\
& \int \rightarrow[+ \text { ant }] /[+ \text { ant, +strid }] \ldots-
\end{aligned}
$$

One of the properties that make sibilant harmony in STz' typologically unusual is that it is progressive (see below) - the trigger always precedes the target. At this juncture, let us consider whether an alternative analysis that does not invoke directionality can characterize the STz' data:

\footnotetext{
${ }^{9}$ Inanimate plural objects need not control plural agreement (see Levin, Lyskawa \& Ranero 2020).
} 


\section{Alternative interpretation of STz' sibilant harmony}

STz' sibilant harmony is stem-controlled, not progressive.

There are empirical and theoretical reasons to entertain (26). Baković (2000) assesses vowel harmony systems cross-linguistically and argues that stem-control gives rise to directionality in harmony systems, but directionality is epiphenomenal. ${ }^{10}$ In a nutshell, progressive harmony arises in languages that employ suffixes because there is a trigger in the stem, which is to the left of a target in the suffixal field. Conversely, regressive harmony arises in languages that employ prefixes because there is a trigger in the stem, which is to the right of a target in the prefixal field. Baković argues that apparent cases of left-to-right (progressive) or right-to-left (regressive) harmony can be reduced to a single mechanism of stem-control, as opposed to two mechanisms (regressive and progressive spread), thus simplifying the grammar. Consider as an illustration sibilant harmony in Koyra (Omotic), which appears to be progressive (much like in STz'). The examples below show that the sibilant in the causative suffix /-(u)s/ surfaces as [-ant] if there is a [-ant] sibilant preceding it $(27 \mathrm{c})$ :

(27) Koyra sibilant harmony (Hayward 1988 cited in Hansson 2010: 274)
a. pug-us- 'cause to blow'
c. go:Tt-uf- 'cause to pull'
b. kes-us- 'cause to go out'

The process in (27) can be analyzed as stem-controlled, as opposed to progressive, given that the trigger is always part of the stem of affixation. Since this is a suffixing context, stem-controlled harmony gives rise to a "progressive" pattern epiphenomenally.

Hansson (2010: 145) notes that seven languages exhibit what appears to be progressive sibilant harmony: Aari, Koyra, Benchnon, Zayse (Omotic); Rumsen (Costanoan); Izere (Bantu); and perhaps Wanka Quechua (Quechuan). However, he observes that sibilant harmony in all these languages can be analyzed as a stem-controlled process, raising the question of whether true leftto-right sibilant harmony exists (see Archangeli \& Pulleyblank 2007: 367 for related discussion). Demi (Omotic; Seyoum 2008) and Sidaama (Cushitic; Kawachi 2007) should also be added to this list, since they are suffixing languages in which the result of sibilant harmony materializes to the right of the stem of affixation.

With this background in mind, two questions arise that serve to evaluate (26) as an analysis of STz' sibilant harmony. First, do we have definitive empirical reasons to reject the encoding of directionality altogether (left-to-right and right-to-left) for the representation of sibilant harmony? Second, can STz' sibilant harmony specifically be analyzed as stem-controlled? The answer to both questions is no.

First, while Baković (2000) shows that most vowel harmony processes can be reduced to stem-control (though see Rose \& Walker 2011), directionality must be invoked to account for several cases of sibilant harmony. Samala (also called Ineseño; Chumashan) illustrates this most clearly. ${ }^{11}$ In this language, the rightmost sibilant in a word determines the $[ \pm$ ant $]$ feature of all sibilants that precede it, whether they be segments in the stem or prefixal field. In the following examples, the stem is underlined, $/ \mathrm{s}-/$ indicates $3^{\text {rd }}$ person subject, /-it/ indicates $1^{\text {st }}$ person object, /-us/ indicates $3^{\text {rd }}$ person object, and /-wa / is a past marker:

\footnotetext{
${ }^{10}$ We set aside dominant-recessive systems, which seem unattested in consonantal harmony (Hansson 2010: 142).

${ }^{11}$ Nkore-Kiga sibilant harmony must also be analyzed as regressive (Hansson 2010: 305-306; but see Bennett \& Pulleyblank 2018), while Navajo sibilant harmony may require such an analysis (Hansson 2010: 277). The data in (30) show that Tseltal's sibilant harmony must be analyzed as right-to-left, since the rightmost sibilant is the trigger.
} 
(28) Samala sibilant harmony is regressive (Applegate 1972 cited in Hansson 2010: 261)
a. /s-api-t t] $]^{\mathrm{h}} \mathrm{O}-\mathrm{it} /$
$\rightarrow\left[\right.$ Japit $\left.{ }^{\mathrm{h}} \mathrm{olit}\right]$
b. /s-api-t $\int^{\mathrm{h}} \mathrm{O}-\mathrm{us} /$
$\rightarrow$ [sapits ${ }^{\mathrm{h}}$ olus]
c. /s-api-t $\int^{\mathrm{h}} \mathrm{O}-\mathrm{us}-\mathrm{waj} /$
$\rightarrow$ [Japit ${ }^{\mathrm{h}}$ olufwaf]
'I have a stroke of good luck.'
'He has a stroke of good luck.'
'He had a stroke of good luck.'

Since directionality must be invoked for sibilant harmony like Samala's - in this case, a right-toleft spread mechanism - this undermines the case for disallowing a left-to-right mechanism $a$ priori. We thus reject a theoretical prior for adopting the alternative in (26) as an analysis of STz' harmony.

Moving to the second question - whether a stem-control analysis holds water at all specifically for STz' sibilant harmony - consider what Hansson (2010: 144) observes about stemcontrolled harmony in general: "the clearest cases of stem-control are those where harmony affects prefixes and suffixes alike, yielding bidirectional harmony 'outwards' from the root." Akan (Niger-Congo, Kwa) vowel harmony illustrates this. Note that the [ \pm ATR] value of the affix vowels below is determined by the stem, which is underlined:

(29) Stem-controlled vowel harmony in Akan (adapted from O'Keefe 2003: 25)
a. $/ \mathrm{O}-\mathrm{bE}-\underline{\mathrm{tu}}-\mathrm{I} / \mathrm{H}$
[obetui] 'he came and dug it'
b. $/ \mathrm{O}-\mathrm{bE}-\underline{\mathrm{t} \mho}-\mathrm{I} / \mathrm{I} \rightarrow$
[obstor] 'he came and threw it'

With this in mind, the data we discussed in section 3 pose a significant challenge to a stem-control analysis of STz' sibilant harmony. Recall that much like Akan, STz' employs both prefixes and suffixes. As we showed, however, STz' is unlike Akan in that the relevant segments in the prefixal field never alternate. This is unexpected for a stem-controlled harmony process. In order for (26) to be descriptively adequate, then, one would need to stipulate that the domain of application for sibilant harmony in STz' excludes three morphemes in the prefixal field: (i) the completive aspect $/ \int-/$, (ii) the potential aspect $/ \mathrm{ft}-/$, and (iii) the B2P agreement $/ \mathrm{i} \int-/$.

At this juncture, one could point out the empirical observation that some sibilant harmony systems do seem to be limited to specific domains - i.e., the root and derivational affixes in Totonacan languages (Hansson 2010: 326). This appears only to be an empirical tendency, however, and given the small number of languages exhibiting sibilant harmony (see (31)), it is unclear whether this tendency reveals something deep about limitations on the representation of sibilant harmony. For instance, data that contrast with the Totonacan pattern are readily available. In Tseltal (Mayan), the effect of sibilant harmony materializes on the incompletive aspect and $\mathrm{A} 3 \mathrm{~S}$ agreement prefixes $(30 \mathrm{~b}-\mathrm{c})$ :

(30) Tseltal sibilant harmony (adapted from Polian 2013: 102-103, 376)
a. /ot $\widehat{\text { fes/ }}$
$\rightarrow$ otses]
'to put in' Venter-CAUS
b. /ja $\int \widetilde{t s}^{\prime}$ ilax/
$\rightarrow$ [ja sts'ilax $]$
INC INC.I- $\sqrt{\text { spoil.B3S }}$
c. $/ \mathbf{s - t}{ }^{\prime}$ ' $u x t$ '/
A3s-womb
$\rightarrow\left[\widehat{\int t}{ }^{\prime} \mathrm{uxt}\right]$
'It spoiled.'
'her womb'

We conclude, then, that (26) fails to characterize sibilant harmony in STz'.

To summarize this section, we considered an alternative analysis of the STz' harmony process that would take it to be stem-controlled, rather than progressive (26). We argued against this analysis, since (i) there is no justification for rejecting the representation of directionality altogether in sibilant harmony and (ii) such an analysis must resort to stipulation. We maintain, then, 
that STz' instantiates an instance of truly progressive sibilant harmony that cannot be reduced to stem control. ${ }^{12}$

4.2. A TYPOLOGY OF TRIGGER CLASSES. Sibilant harmony patterns may be divided into three types based on the class of segments that triggers the process (Hansson 2010: 356-367). ${ }^{13}$ To Hansson's typology below, we add Slovenian (Jurgec 2011; see Hansson 2020), Dime (Seyoum 2008; see Hansson 2010: 50), and Sidaama (Kawachi 2007; see Rose 2011) as type (31b) languages, and move Tseltal from type (31b) to (31a). Finally, we add STz' to type (31c): ${ }^{14}$

(31) Sibilant harmony typology based on trigger type (modified from Hansson 2010: 356-367) a. symmetrical: both [+ant] and [-ant] sibilants are triggers

b. asymmetrical: only [-ant] triggers (e.g., $\int=$ trigger)

c. asymmetrical: only [+ant] triggers (e.g., $\mathrm{s}=$ trigger)

10-11 languages

18 languages

2 languages

In what we have termed type (31a), Hansson identifies the following: Navajo, Chiricahua Apache, Plains Apache, Tanana (Athabaskan), Barbareño, Samala, Ventureño (Chumashan), Southern Paiute (Uto-Aztecan), Nebaj Ixil (Mayan), and possibly Misantla Totonac (Totonac); we add Tseltal (Mayan). The second type (31b) seems to be the most common. Hansson identifies several languages (some with multiple dialects) that fit this type: Tsuut'ina, Dene-tha (Athabaskan), Wiyot (Algic), Aari, Koyra, Benchnon, Zayse (Omotic), Moroccan Arabic (Semitic), Berber (various dialects; Afro-Asiatic), Coptic (various dialects; Afro-Asiatic), NkoreKiga, Rwanda, Rundi, Shambaa and Izere (Bantu); we add Slovenian (Slavic), Dime (Omotic), and Sidaama (Cushitic).

As is clear from (31), languages are unevenly distributed across the possible types, an empirical observation that has the potential to shed light on the source and representation of sibilant harmony processes. What is most interesting for our purposes is the dearth of languages in type (31c). Before our addition of STz' to type (31c), Hansson (2010) had identified a single language where only [+ant] sibilants are triggers: Tlachichilco Tepehua (Totonacan).${ }^{15}$ As shown below, sibilant harmony is regressive in Tlachichilco Tepehua, unlike in STz':

12 Other cases that might qualify are Navajo, which may have progressive harmony within the prefixal field (see Hansson 2010: 148-152 for discussion and qualifications) and Teralfene Flemish (Hansson 2010: 145), though the latter requires more investigation. We leave a formalization of the representation of truly progressive harmony for the future. Note that certain models of consonantal harmony are built to disallow genuine progressive systems; see Hansson (2010: 261-294) for discussion.

${ }^{13}$ This typology excludes languages with sibilant co-occurrence restrictions in roots that may or may not evidence a synchronically active process.

${ }^{14}$ Hansson (2010) notes that classifying some languages as (31b) instead of (31a) can be an analytical choice. For instance, two languages classified as (31b) by Hansson (Nkore-Kiga and Tseltal) actually exhibit a symmetrical system. However, Hansson claims that [+ant] triggers are more restricted than [-ant] ones. For example, he argues that Tseltal exhibits $\int \rightarrow \mathrm{s}$ only if the target is sandwiched between two /s/ triggers (Kaufman 1971):

(i) $\quad / \mathbf{s}$-wàkaj $/ \rightarrow[$ fwáka $] \quad$ 'his cattle'

(iii) $\quad / \mathbf{f}$-pàs-H/ $\rightarrow$ [spás $] \quad$ 'it is made'

(ii)

/s-kùf-H-es-ik/ $\rightarrow$ [skúsesik]

'they revive'

Example (ii) leads Hansson to classify Tseltal as an asymmetrical type (31b) language rather than (31a). However, (iii) above from Kaufman seems to show that the [+ant] trigger need not surround the target on both sides. This data point and the description in Polian (2013) (see (30)) lead us to classify Tseltal as a (31a) language.

${ }^{15}$ Hansson (2010: 46) observes that Tz'utujil has sibilant harmony (citing Dayley 1985), but he does not classify the pattern into his typology. On page 389, he classifies Tz'utujil sibilant harmony as being a static morpheme structure constraint on roots, so Hansson must have been referencing syllable internal co-occurrence restrictions (Dayley 1985: 31), rather than the rule in (1); see section 5 below. 
(32) Tlachichilco Tepehua sibilant harmony (Watters 1988 cited in Hansson 2010: 360)
a. / Paqf-kis/ $\rightarrow$ [?aqskis $]$
CLF-five

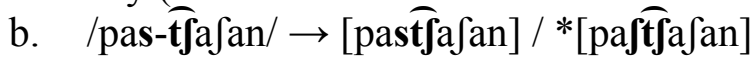
CLF-six
'five flat things'
'six bundles'

Hansson argues that the relative rarity of type (31c) languages is not accidental, linking it instead to the Palatal Bias - a robust empirical generalization related to speech errors in production:

Palatal Bias in relation to sibilants (Shattuck-Hufnagel \& Klatt 1979)
Speech errors involving substitutions like $s \rightarrow \int$ are much more common than $\int \rightarrow \mathrm{s}$

In a nutshell, Hansson claims that whatever mechanism underlies the Palatal Bias (an empirical observation) also gives rise to sibilant harmony. We therefore expect more languages where sibilant harmony gives rise to $\mathrm{s} \rightarrow \int$ only (31b), as opposed to $\int \rightarrow \mathrm{s}$ only (31c).

In light of this proposal, Hansson must explain the existence of Tepehua harmony, which is $\int \rightarrow \mathrm{s}$ (31c). He speculates that Tepehua harmony has an extraordinary diachronic source: it arose from the grammaticalization of a language-specific sound symbolism pattern. Totonacan languages are characterized by sibilant alternations within a stem, where a stem with a [-anterior] sibilant maps to a meaning indicating a greater intensity than a stem with a [+anterior] sibilant:

(34) Sound symbolism in North Central Totonac of Apapantilla, Puebla (MacKay 1994)
a. [tsutsu] 'she smokes'
b. [tfutfu] 'she sucks'

Hansson proposes that Tlachichilco Tepehua speakers reanalyzed a sound symbolism pattern as a purely grammatical process. The pattern of $\int \rightarrow \mathrm{s}$ harmony in Tepehua is therefore not a challenge to the claim that whatever underlies the Palatal Bias also gives rise to sibilant harmony. Instead, it is an outlier that can be explained independently (see Hansson 2010: 360-363).

STz', however, is a type (31c) language for which we cannot invoke an extraordinary diachronic source - e.g., there is no sound symbolism mechanism that could explain the outlier nature of the STz' process. Nevertheless, let us point out a characteristic of STz' grammar that might contribute to the diachronic stability of its sibilant harmony: the $/ \int /$ in which the harmony process materializes is always in the final syllable of the word, which bears stress:

$$
\begin{aligned}
& \mathrm{STz} \text { ' is stress-final (data repeated from }(19)) \\
& / \int \text {-in-sin-6aa-V } \int-\mathrm{a} / \quad \rightarrow \quad[\text { in.sin.6aa.sá] }
\end{aligned}
$$

We conjecture that this property of STz' grammar makes the $\int \rightarrow \mathrm{s}$ alternation particularly salient for the learner. If we assume that whatever underlies the Palatal Bias would make the STz' pattern diachronically unstable, then this particular characteristic of STz' grammar - the fact that the target of harmony always occurs in the final syllable - has contributed to the pattern's stability over generations of transmission.

We end by noting that adding a single new outlier to the typology in (31) does not conclusively cast doubt on Hansson (2010)'s proposal connecting the mechanism underlying the Palatal Bias to the skewed patterning of sibilant harmony cross-linguistically. However, it appears that more detailed work in the Mayan family could establish even more examples of the rare (31c) 
type. For example, DuBois (1981) briefly notes that Sakapultek, another language of the K'ichean branch, appears to exhibit the same sibilant harmony system as STz': ${ }^{16}$

(36) Sakapultek sibilant harmony (adapted from DuBois 1981: 137, 207)
a. $/$ tsili-j/ $\quad \rightarrow \quad[$ tsilis $]$
'it was returned'
$\checkmark$ return-PASS
b. $/$ kuPum-asa-j/ $\rightarrow$
[kuPmasas] 'it was moved'
c. /r-ts'unu-f-iik/ $\rightarrow$
A3s- $\sqrt{\text { ask.for-PASS-NMLZ }}$
'its being asked for'

At present, we do not have as detailed a description for Sakapultek as we do for STz', so we hesitate to conclude that a third language should be added to type (31c). DuBois (1981: 46) suggests that the same sibilant harmony process also exists in Poqom (K'ichean), though we have been unable to find corroboration in published sources (e.g., Santos Nicolás \& Benito Pérez 1998; Malchic Nicolás, Mó Isém \& Tul Rax 2000). Romelia Mó Isém and Carlos Humberto Cú Cab (p.c.) also point out to us that some dialects of Q'eqchi (K'ichean) have the same sibilant harmony process, though this has not been documented either.

To summarize, we added STz' to the typological distribution of sibilant harmony based on trigger type, showing that it is one of two outlier languages where only [+ant] sibilants are triggers. We laid out Hansson's (2010) proposal that linked the scarcity of type (31c) languages to the mechanism underlying the Palatal Bias and conjectured that the stress-pattern in STz' might explain how the sibilant harmony process in the language has been stable diachronically.

5. Conclusions and future work. We showed that STz' exhibits a typologically unique process of sibilant harmony. The combination of properties that make it an outlier are the following: the process (i) is triggered solely by [+ant] sibilants, (ii) is progressive, and (iii) cannot be reduced to stem-control.

Our work toward understanding STz' sibilant harmony is not done, however. We end by noting an exception to the pattern we described. There is at least one instance of root-internal sibilant disharmony, the root /sat $\mathrm{f} /$ 'to lose':

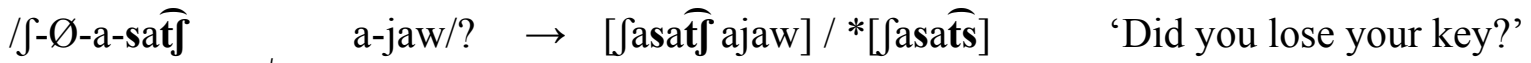

$$
\begin{aligned}
& \text { COM-B3S-A2s- } \sqrt{\text { lose }} \text { A2s-key }
\end{aligned}
$$

Interestingly, this root only passivizes via the infix /-P-/, not /-VS/, and combines with the /-ik/ allomorph of the nominalizer, not /-fik/. We therefore cannot determine whether the trigger can "skip" the / $/ \mathrm{f} /$ segment in the root and trigger assimilation on a segment in the suffixal field:
a. $/ \int-$ in-sa $<$ ? $>\overparen{\mathrm{t} \int}-\mathrm{a} / \rightarrow[$ [insa?at $\widetilde{\mathrm{t}} \mathrm{a}]$
COM-B $1 \mathrm{~S}-\sqrt{\text { lose }}<$ PASS $>$-INTR
'I got lost.'
b. /ruu-sat $\widetilde{-i k} / \rightarrow$ [rsat $\widetilde{1 i k}]$ A3s- $\sqrt{ }$ lose-NMLZ 'its losing'

To put (37) in context, Dayley (1985: 31) noted a restriction on the root-internal co-occurrence of sibilants disagreeing in anteriority in San Juan Tz'utujil. In Pérez Mendoza \& Hernández Mendoza (2001), we indeed do not find any root internal combination of two sibilants where the

\footnotetext{
${ }^{16}$ Hansson does not discuss Sakapultek. In contrast to DuBois (1981), a more recent grammar (Mó Isém 2007) does not describe sibilant harmony. Romelia Mó Isém (p.c.) informs us that she did not document any such process in her fieldwork, nor does she recall eliciting data akin to DuBois's.
} 
sibilants disagree in [ \pm ant], except for $\sqrt{s V t}_{\mathbf{t}}$, as illustrated by (37) for STz'- see e.g., the entry $<$ sachooj $>$ 'to confuse'. In brief, there seem to be no instances in the dictionary of roots where the first sibilant is [+ant] and the second is [-ant]: $\sqrt{\mathrm{sV}} \int, \sqrt{\mathrm{s} V \mathrm{t}}{ }^{\prime}, \sqrt{\mathrm{ts}} \mathrm{V} \int, \sqrt{\mathrm{ts} V \mathrm{t}}, \sqrt{\mathrm{ts}} \widehat{\mathrm{tt}^{\prime}}, \sqrt{\mathrm{ts}^{\prime} \mathrm{V} \int}$, $\sqrt{\mathrm{ts}^{\prime} \mathrm{Vt} f}, \sqrt{\mathrm{ts}^{\prime} \mathrm{Vtf}^{\prime}}$. In a similar manner, we also do not find any instance of roots where the first sibilant is [-ant] and the second is [+ant]: $\sqrt{ } \rho \mathrm{Vs}, \sqrt{\rho \mathrm{Vts}}, \sqrt{\rho} \widehat{\mathrm{Vts}^{\prime}}, \sqrt{\mathrm{t} f \mathrm{Vs}}, \sqrt{\mathrm{t} \rho \mathrm{Vts}}, \sqrt{\mathrm{t} \int \mathrm{Vts}}, \sqrt{\mathrm{t} \mathrm{f}^{\prime}} \mathrm{Vs}$, $\sqrt{\mathrm{t} \int}$ ' $\widehat{\mathrm{ts}}, \sqrt{\mathrm{t}}{ }^{\prime} \mathrm{Vts}$ '. In our work on STz', we have never documented a root with these forms either.

The significance of the disharmonic root in (37) is unclear to us at this point. For instance, it could simply be a lexical exception. Alternatively, it might indicate that only a subset of [-ant] sibilants in STz' are targets, to the exclusion of $\widetilde{\mathrm{t} f} /$. We leave for future work whether (37) is the only lexical outlier or whether root-internal disharmony in STz' is more frequent.

\section{References}

Applegate, Richard B. 1972. Ineseño Chumash grammar. Berkeley, CA: University of California dissertation.

Archangeli, Diana \& Douglas Pulleyblank. 2007. Harmony. In Paul de Lacy (ed.), The Cambridge handbook of phonology. Cambridge: Cambridge University Press.

Baković, Eric. 2000. Harmony, dominance and control. New Brunswick, NJ: Rutgers University dissertation.

Baron, Christopher, Paulina Lyskawa \& Rodrigo Ranero. 2020. Narcissistic allomorphy in Santiago Tz'utujil. Handout presented at the Meeting of the Society for the Study of the Indigenous Languages of the Americas, New Orleans, LA.

Bennett, Wm. G. \& Douglas Pulleyblank. 2018. Directionality in Nkore-Kiga sibilant harmony: Arbitrary or emergent? Linguistic Inquiry 49(1). 1-22. https://doi.org/10.1162/LING_a_00264.

Burukina, Irine \& Alexandra Kubatieva. 2021. On the nature of arguments in event nominals. Handout presented at the 95th Annual LSA Meeting.

Can Pixabaj, Telma Angelina. 2015. Complement and purpose clauses in K'iche'. Austin, TX: University of Texas dissertation.

Dayley, Jon Philip. 1985. Tzutujil grammar. Berkeley, CA: University of California Press.

DuBois, J. W. 1981. The Sacapultec language. Berkeley, CA: University of California dissertation.

England, Nora C. \& Brandon O. Baird. 2017. Phonology and phonetics. In Judith Aissen, Nora C. England \& Roberto Zavala Maldonado (eds.), The Mayan languages. New York: Routledge.

García Ixmatá, Pablo (Ajpub'). 1997. Gramática tz'utujiil. Guatemala: Editorial Cholsamaj.

García Ixmatá, Pablo (Ajpub'). 1998. Jotaytziij tz’utujiil: Derivación de palabras tz'utujiil. Guatemala: Editorial Cholsamaj.

Hansson, Gunnar Ólafur. 2010. Consonant harmony: Long-distance interactions in phonology. Berkeley, CA: University of California Press.

Hansson, Gunnar Ólafur. 2020. Consonant harmony. In Mark Aronoff(ed.), Oxford research encyclopedia of linguistics. Oxford: Oxford University Press.

Hayward, Richard J. 1988. Remarks on Omotic sibilants. In Marianne Bechhaus-Gerst \& Fritz Serzisko (eds.), Cushitic-Omotic, 263-299. Hamburg: Helmut Buske Verlag.

Henderson, Robert. 2019. The roots of measurement. Glossa: A Journal of General Linguistics 4(1). 1-31. https://doi.org/10.5334/gjgl.515.

Imanishi. 2014. Default ergative. Cambridge, MA: MIT dissertation. 
Jurgec, Peter. 2011. Feature spreading 2.0: A unified theory of assimilation. Tromsø, NO: University of Tromsø dissertation.

Kaufman, Terrence. 1971. Tzeltal phonology and morphology. Berkeley, CA: University of California Press.

Kawachi, Kazuhiro. 2007. A grammar of Sidaama (Sidamo), a Cushitic language of Ethiopia. Buffalo, NY: State University of New York dissertation.

Levin, Theodore, Paulina Lyskawa \& Rodrigo Ranero. 2020. Optional agreement in Santiago Tz'utujil (Mayan) is syntactic. Zeitschrift für Sprachwissenschaft 39(3). 329-355. https://doi.org/10.1515/zfs-2020-2018.

Lyskawa, Paulina \& Rodrigo Ranero. 2021a. Optional agreement as successful/failed AGREE: Evidence from Santiago Tz'utujil (Mayan). To appear in Linguistic Variation.

Lyskawa, Paulina \& Rodrigo Ranero. 2021b. Vowel harmony in Santiago Tz'utujil (Mayan). Handout presented at the Meeting of the Society for the Study of the Indigenous Languages of the Americas.

MacKay, Carolyn J. 1994. A sketch of Misantla Totonac phonology. International Journal of American Linguistics 60(4). 369-419. https://doi.org/10.1086/466242.

Malchic Nicolás, Manuel Bernardo, Ixmaak' Romelia Mó Isém \& Raxchee’Augusto Tul Rax. 2000. Rub'iral ruk'ihaal wach poqom q'orb'al: Variación dialectal en poqom. Guatemala: Editorial Cholsamaj.

O'Keefe, Michael. 2003. Akan vowel harmony. Philadelphia: Swarthmore College Bachelor's thesis.

Paster, Mary. 2014. Allomorphy. In Rochelle Lieber \& Pavol Štekauer (eds.), The Oxford handbook of derivational morphology. Oxford: Oxford University Press.

Pérez Mendoza, Francisco \& Miguel Hernández Mendoza. 2001. Diccionario tz'utujil. Guatemala City: Editorial Cholsamaj.

Polian, Gilles. 2013. Gramática del tseltal de Oxchuc. México: CIESAS.

Polian, Gilles. 2017. Morphology. In Judith Aissen, Nora C. England \& Roberto Zavala Maldonado (eds.), The Mayan languages. New York: Routledge.

Rose, Sharon. 2011. Long-distance assimilation of consonants. In Marc van Oostendorp, Colin J. Ewen, Elizabeth Hume \& Keren Rice (eds.), The Blackwell companion to phonology. Malden, MA: Wiley-Blackwell.

Rose, Sharon \& Rachel Walker. 2004. A typology of consonant agreement as correspondence. Language 80(3). 475-531. https://doi.org/10.1353/lan.2004.0144.

Rose, Sharon \& Rachel Walker. 2011. Harmony systems. In John Goldsmith, Jason Riggle \& Alan Yu (eds.), Handbook of phonological theory, 240-290. Second Edition. Oxford: WileyBlackwell.

Santos Nicolás, Pala's José Francisco \& Waykan José Gonzalo Benito Pérez. 1998. Ruk'orb'aal poqom q'orb'al: Gramática poqom (poqomam). Guatemala: Editorial Cholsamaj.

Seyoum, Mulugeta. 2008. A grammar of Dime. Leiden: Leiden University dissertation.

Shattuck-Hufnagel, S. \& D. H. Klatt. 1979. The limited use of distinctive features and markedness in speech production: Evidence from speech error data. Journal of Verbal Learning and Verbal Behaviour 18. 41-55. https://doi.org/10.1016/s0022-5371(79)90554-1.

Watters, James. 1988. Topics in Tepehua grammar. Berkeley, CA: University of California dissertation. 